\title{
Resposta da Aveia Branca à Adubação em Latossolo Vermelho-Amarelo em Dois Sistemas de Plantio
}

\author{
Ana Cândida Primavesi ${ }^{1}$, Odo Primavesi ${ }^{1,3}$, Heitor Cantarella ${ }^{2,3}$, Rodolfo Godoy ${ }^{1}$
}

RESUMO - Com a finalidade de determinar as doses de N, P e K para obter a máxima produção econômica de forragem para a linhagem UPF 87111, nos sistemas de plantio convencional e plantio com cobertura morta, foram instalados experimentos em Latossolo VermelhoAmarelo Distrófico típico, em São Carlos, SP. O delineamento experimental foi o fatorial fracionado tipo (1/2) $4^{3}$ com dois blocos ao acaso, total de 32 parcelas, sem repetição. Os tratamentos foram quatro doses de $\mathrm{N}$ e de $\mathrm{K}_{2} \mathrm{O}\left(0,70,140\right.$ e $\left.210 \mathrm{~kg} \mathrm{ha}^{-1}\right)$, como uréia e cloreto de potássio, e quatro doses de $\mathrm{P}_{2} \mathrm{O}_{5}\left(0,60,120,180 \mathrm{~kg} \mathrm{ha}^{-1}\right)$, como superfosfato triplo. As doses de $\mathrm{N}$, $\mathrm{P}$ e $\mathrm{K}$ para a produção de forragem de aveia com máxima receita líquida foram, em kg ha ${ }^{-1}$ para o plantio convencional: $\mathrm{N}=160, \mathrm{P}_{2} \mathrm{O}_{5}=180, \mathrm{~K}_{2} \mathrm{O}=180$ e para o plantio com cobertura morta: $\mathrm{N}=200, \mathrm{P}_{2} \mathrm{O}_{5}=120, \mathrm{~K}_{2} \mathrm{O}=95$, com produções de matéria seca de, respectivamente, $7.398 \mathrm{~kg} \mathrm{ha}^{-1}$ e $8.111 \mathrm{~kg} \mathrm{ha}^{-1}$.

Palavras-chave: Avena sativa, fósforo, nitrogênio, potássio, produção de forragem

\section{Response of Oats to Fertilization on Red Yellow Latosol in Two Planting Systems}

\begin{abstract}
Two field experiments were carried out on a Red Yellow Latosol (Hapludox), at São Carlos, SP in order to determine the rates of $\mathrm{N}, \mathrm{P}$, and $\mathrm{K}$ to obtain maximum economic return per area of forage yield for the oat line UPF 87111 grown in two planting systems: conventional tillage and mulch-covered. The experimental design was a fractionated factorial type (1/2) $4^{3}$, with two blocks. The treatments consisted of four rates of $\mathrm{N}$ and $\mathrm{K}_{2} \mathrm{O}\left(0,70,140\right.$, and $\left.210 \mathrm{~kg} \mathrm{ha}^{-1}\right)$, using urea and potassium chloride, and four rates of $\mathrm{P}_{2} \mathrm{O}_{5}\left(0,60,120\right.$ and $\left.180 \mathrm{~kg} \mathrm{ha}^{-1}\right)$, using triple superphosphate. The $\mathrm{N}, \mathrm{P}$, and $\mathrm{K}$ rates for maximum profit were, in $\mathrm{kg}$ ha ${ }^{-1}$ for conventional tillage: $\mathrm{N}=160, \mathrm{P}_{2} \mathrm{O}_{5}=180, \mathrm{~K}_{2} \mathrm{O}=180$; and for mulch-covered: $\mathrm{N}=200, \mathrm{P}_{2} \mathrm{O}_{5}=120, \mathrm{~K}_{2} \mathrm{O}=95$ resulting in forage yields of, respectively, 7,398 and $8,111 \mathrm{~kg} \mathrm{ha}^{-1}$ of dry matter. In both planting systems, the use of nitrogen resulted in higher forage yield per unit of applied fertilizer.
\end{abstract}

Key Words: Avena sativa, forage yield, nitrogen, phosphorus, potassium

\section{Introdução}

A aveia branca é uma forrageira de inverno que apresenta grande potencial de utilização na alimentação animal no Estado de São Paulo, podendo se tornar importante componente em sistemas de produção agrícolas, contribuindo para a maior sustentabilidade desses sistemas, pois possibilita a integração lavourapecuária, em semeadura direta.

No Estado de São Paulo, a expansão da prática do plantio direto na palha gera a demanda de informações sobre a comparação desse sistema de plantio com o sistema convencional. O recobrimento do solo com resíduos de cultura é um dos aspectos importantes do plantio direto, pois provoca modificação do microclima para as plantas cultivadas. Com cobertura morta pode-se diminuir a freqüência de irrigações no cultivo de aveia, o que reduziria os custos de produção, pois a cobertura morta tem influência no regime hidrotérmico do solo, conserva a umidade (Sediyama \& Prates, 1986), reduz a evaporação (Vieira, 1981) e aumenta a infiltração de água no solo e, indiretamente, controla as ervas daninhas (Almeida, 1981). Como a cobertura morta também reduz a temperatura (Unger, 1978), além de apresentar outros efeitos na biologia do solo e disponibilidade de nutrientes, a sua presença torna os primeiros centímetros do solo um ambiente mais adequado biologicamente, com maior desenvolvimento de raízes superficiais (Resende, 1986), podendo haver modificações na resposta das plantas à adição de nutrientes no solo por meio da adubação (Kochhann \& Denardin, 1997).

A linhagem de aveia UPF 87111 destaca-se na seleção de linhagens de aveia forrageira (Godoy et

\footnotetext{
1 Embrapa Pecuária Sudeste, Caixa Postal 339, CEP: 13560-970, São Carlos, SP.

E.mail: anacan@cppse.embrapa.br; odo@cppse.embrapa.br; godoy@cppse.embrapa.br

${ }^{2}$ Centro de Pesquisa e Desenvolvimento de Solos e Recursos Ambientais, IAC, Caixa Postal 28, CEP: 13001-970, Campinas, SP.

E.mail: cantarella@iac.sp.gov.br

${ }^{3}$ Bolsista do CNPq.
} 
al., 1998) e será lançada como novo cultivar para o Estado de São Paulo. Este trabalho foi conduzido com a finalidade de determinar as doses de N, P e K que possibilitem obter a máxima produção econômica de forragem para linhagem, nos dois sistemas de semeadura convencional e com recobrimento do solo com cobertura morta, simulando condições que ocorrem em plantio direto, para oferecer ao produtor opções de adubação para aveia, conforme o sistema de plantio a ser adotado.

\section{Material e Métodos}

Os experimentos foram conduzidos em Latossolo Vermelho-Amarelo Distrófico típico (LVAd), textura média, na Embrapa Pecuária Sudeste, São Carlos, SP, em altitude de $836 \mathrm{~m}$, sob clima tropical de altitude, e déficit hídrico no período de outono-inverno.

Os experimentos foram irrigados com base no balanço entre a demanda climática e as condições edáficas do local (Rassini, 2001). O delineamento experimental (Tabela 1) foi o fatorial fracionado tipo $(1 / 2) 4^{3}$ com dois blocos ao acaso, em um total de 32 parcelas, sem repetição, de acordo com Andrade \& Noleto (1986). Os tratamentos constaram de quatro doses de $\mathrm{N}$ e de $\mathrm{K}_{2} \mathrm{O}\left(0,70,140\right.$ e $\left.210 \mathrm{~kg} \mathrm{ha}^{-1}\right)$, na forma de uréia e de cloreto de potássio, e quatro doses de $\mathrm{P}\left(0,60,120,180 \mathrm{~kg} \mathrm{ha}^{-1}\right.$ de $\left.\mathrm{P}_{2} \mathrm{O}_{5}\right)$, como superfosfato triplo. As doses de $\mathrm{P}$ foram aplicadas no plantio $(15 / 05 / 01)$ e as de $\mathrm{N}$ e de $\mathrm{K}_{2} \mathrm{O}(70,140$ e $210 \mathrm{~kg} \mathrm{ha}^{-1}$ ) foram parceladas, respectivamente, no plantio em 15/05/01 (10, 20 e $\left.30 \mathrm{~kg} \mathrm{ha}^{-1}\right)$, no perfilhamento em 13/06/01 (15, 30 e $\left.45 \mathrm{~kg} \mathrm{ha}^{-1}\right)$, após o primeiro corte em 04/07/01 (15, 30 e $\left.45 \mathrm{~kg} \mathrm{ha}^{-1}\right) \mathrm{e}$ após os cortes de rebrota em 08/08/01 e 12/09/01 (15, 30 e $45 \mathrm{~kg} \mathrm{ha}^{-1}$ ).

As áreas do experimentos eram contíguas. Foi feita uma amostragem de solo da área do experimento em 24/11/00. Não houve necessidade de aplicar calcário no solo. A área do experimento destinada ao plantio convencional foi mantida em pousio por um ano, sendo roçada e rastelada. Nova coleta de terra da área foi feita em 10/04/01, seguida por uma gradagem. Em 15/05/01, o terreno foi novamente revolvido com enxada rotativa e o experimento, instalado. $\mathrm{Na}$ área destinada à aveia semeada em solo com cobertura morta, a cultura anterior foi o milho cultivado sem adubação, com a finalidade de obter essa cobertura. Em 11/04/01, foi coletada amostra de terra, colhidas as espigas de milho e roçada a área.
Em seguida, os restos culturais foram pesados (9115 $\mathrm{kg} \mathrm{ha}^{-1}$ de matéria seca), picados e redistribuídos uniformemente na área, que não recebeu qualquer revolvimento mecânico além da abertura dos sulcos para o plantio da aveia. Em 15/05/01, foi feito o plantio da aveia. A terra coletada da área dos dois experimentos foi analisada pelos métodos descritos por Van Raij et al. (2001) (Tabela 2).

As parcelas foram constituídas de cinco linhas de $6 \mathrm{~m}$ espaçadas de $20 \mathrm{~cm}$ e área útil de $3 \mathrm{~m}^{2}$. A

Tabela 1 - Descrição dos tratamentos nos dois blocos com as quantidades totais de nutrientes aplicados

Table 1 - Total applied nutrient on each treatment on two blocks

\begin{tabular}{lccc}
\hline Tratamentos & \multicolumn{3}{c}{ Nutrientes } \\
\cline { 2 - 4 } Treatments & $\mathrm{N}$ & $\mathrm{P}_{2} \mathrm{O}_{5}$ & $\mathrm{~K}_{2} \mathrm{O}$ \\
& \multicolumn{2}{c}{ Nutrients } \\
\hline
\end{tabular}

Bloco 1

Block 1

$\begin{array}{cccc}000 & 0 & 0 & 0 \\ 011 & 0 & 60 & 70 \\ 022 & 0 & 120 & 140 \\ 033 & 0 & 180 & 210 \\ 101 & 70 & 0 & 70 \\ 110 & 70 & 60 & 0 \\ 123 & 70 & 120 & 210 \\ 132 & 70 & 180 & 140 \\ 202 & 140 & 0 & 140 \\ 213 & 140 & 60 & 210 \\ 220 & 140 & 120 & 0 \\ 231 & 140 & 180 & 70 \\ 303 & 210 & 0 & 210 \\ 312 & 210 & 60 & 140 \\ 321 & 210 & 120 & 70 \\ 330 & 210 & 180 & 0\end{array}$

Bloco 2

Block 2

$003 \quad 0 \quad 0 \quad 210$

012

021

030

102

120

113

131

201

210

223

232

300

311

322

333

$\begin{array}{ccc}0 & 0 & 210 \\ 0 & 60 & 140 \\ 0 & 120 & 70 \\ 0 & 180 & 0 \\ 70 & 0 & 140 \\ 70 & 120 & 0 \\ 70 & 60 & 210 \\ 70 & 180 & 70 \\ 140 & 0 & 70 \\ 140 & 60 & 0 \\ 140 & 120 & 210 \\ 140 & 180 & 140 \\ 210 & 0 & 0 \\ 210 & 60 & 70 \\ 210 & 120 & 140 \\ 210 & 180 & 210\end{array}$


semeadura foi manual, com 70 sementes viáveis por metro linear, em sulcos com $3 \mathrm{~cm}$ de profundidade. Foi usada a linhagem de aveia branca UPF 87111, que apresenta ciclo longo e alta produtividade de forragem. Os cortes das plantas foram manuais, feitos a $10 \mathrm{~cm}$ da superfície do solo. O primeiro corte foi efetuado quando $10 \%$ das plantas iniciaram o alongamento do colmo e os três cortes de rebrotas, com intervalos de 35 dias (Primavesi et al., 2001a).

A matéria fresca da parcela foi pesada e uma amostra de $500 \mathrm{~g}$ foi secada em estufa com circulação forçada de ar a $60^{\circ} \mathrm{C}$ até peso constante, para determinar o teor de água e calcular a produção de matéria seca.

Os dados foram analisados por meio de regressão e de variância da regressão, usando, respectivamente, os procedimentos REG e GLM do pacote estatístico SAS (1993). Para as produções de cada experimento, por meio do modelo polinomial quadrático, ajustaram-se funções da superfície de resposta do tipo $\mathrm{Y}=\mathrm{b}_{0}+$ $\mathrm{b}_{1} \mathrm{~N}+\mathrm{b}_{2} \mathrm{~N}^{2}+\mathrm{b}_{3} \mathrm{P}+\mathrm{b}_{4} \mathrm{P}^{2}+\mathrm{b}_{5} \mathrm{~K}+\mathrm{b}_{6} \mathrm{~K}^{2}+\mathrm{b}_{7} \mathrm{NP}+$ $\mathrm{b}_{8} \mathrm{NK}+\mathrm{b}_{9} \mathrm{PK}$, em que $\mathrm{Y}$ é a produção de matéria seca de forragem $\left(\mathrm{t} \mathrm{ha}{ }^{-1}\right) ; b_{i}$, os coeficientes de regressão; e $\mathrm{N}, \mathrm{P}$ e $\mathrm{K}$, as doses de $\mathrm{N}, \mathrm{P}_{2} \mathrm{O}_{5}$ e $\mathrm{K}_{2} \mathrm{O}$, em $\mathrm{kg} \mathrm{ha}^{-1}$, respectivamente.

As doses e as combinações de nutrientes para máxima produção foram obtidas por meio do cálculo diferencial $\partial \mathrm{Y} / \partial \mathrm{N}=0, \partial \mathrm{Y} / \partial \mathrm{P}=0 \mathrm{e} \partial \mathrm{Y} / \partial \mathrm{K}=0 \mathrm{e}$ para o lucro máximo, calculadas por $\partial \mathrm{Y} / \partial \mathrm{N}=\mathrm{V} / \mathrm{C}_{\mathrm{N}}$, $\partial \mathrm{Y} / \partial \mathrm{P}=\mathrm{V} / \mathrm{C}_{\mathrm{P}}$ e $\partial \mathrm{Y} / \partial \mathrm{K}=\mathrm{V} / \mathrm{C}_{\mathrm{K}}$, em que $\mathrm{V}$ é o preço de $1 \mathrm{~kg}$ de matéria seca de forragem e $\mathrm{C}_{\mathrm{N}}, \mathrm{C}_{\mathrm{P}}$ e $\mathrm{C}_{\mathrm{K}}$, o preço de $1 \mathrm{~kg}$ de $\mathrm{N}, \mathrm{P}_{2} \mathrm{O}_{5}$ e $\mathrm{K}_{2} \mathrm{O}$, respectivamente. Para os cálculos do retorno econômico, foram considerados os seguintes preços: feno de aveia $=$ $\mathrm{R} \$ 0,22 \mathrm{~kg}^{-1} ; \mathrm{N}=\mathrm{R} \$ 1,07 \mathrm{~kg}^{-1} ; \mathrm{P}_{2} \mathrm{O}_{5}=\mathrm{R} \$ 1,38 \mathrm{~kg}^{-1}$ e $\mathrm{K}_{2} \mathrm{O}=\mathrm{R} \$ 0,82 \mathrm{~kg}^{-1}$.

\section{Resultados e Discussão}

A análise de variância indicou resposta para o nitrogênio e fósforo nos dois sistemas de plantio: convencional e com cobertura morta, e para $\mathrm{K}$ apenas no sistema de plantio convencional. Foi observada interação $\mathrm{N}$ x $\mathrm{P}$ positiva significativa, para os dois sistemas de plantio. No sistema de plantio com cobertura morta, a resposta ao nitrogênio era esperada, pois, se a palhada do milho estiver com alta relação $\mathrm{C} / \mathrm{N}$, ocorre demanda por maior aporte de nitrogênio (Sá, 1993).

Constam na Tabela 3 as produções de forragem, referentes à soma dos quatro cortes, e na Tabela 4, os dados de produção de forragem de aveia por corte e

Tabela 2 - Resultados das análises químicas em três profundidades e textural do solo, anterior à instalação dos experimentos

Table 2 - Soil chemical analysis in three depths and textural analysis, prior to the experiments installation

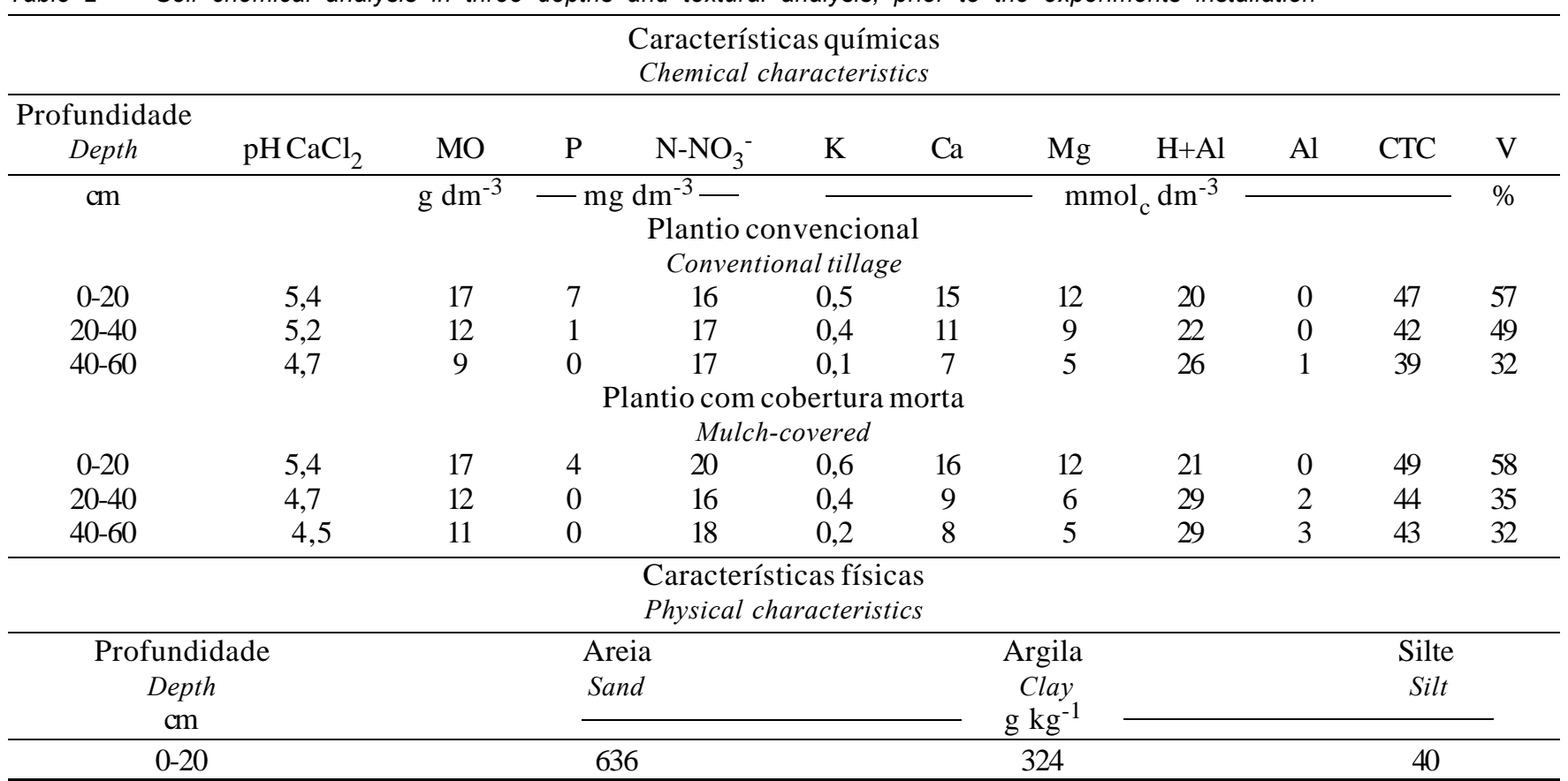


total, nos dois sistemas de plantio.

Nos dois sistemas de plantio, as produções de forragem nas doses máximas utilizadas de $\mathrm{N}$ sugerem a proximidade do ponto de máxima (Tabela 4). A análise de variância indicou resposta quadrática para esse nutriente. Frizzone et al. (1995) conduziram experimento em Latossolo Vermelho-Escuro, Pirassununga/SP, e verificaram, em aveia para forragem, resposta quadrática à aplicação de nitrogênio com valor máximo estimado de produção de $6,9 \mathrm{t} \mathrm{ha}^{-1}$ para a dose de $152 \mathrm{~kg} \mathrm{ha}^{-1}$ de nitrogênio.

Com os cortes realizados no mesmo dia para todos os tratamentos, após o primeiro corte as plantas de aveia de alguns tratamentos (os que não receberam fósforo) rebrotaram mais rapidamente que nos outros tratamentos, porque a maior parte dos meristemas apicais não foi eliminada. Nos outros tratamentos em que as plantas cresceram mais e a

Tabela 3 - Produção de matéria seca total dos quatro cortes nos dois sistemas de plantio Table 3 - Total dry matter yield of four cuttings on both planting systems

\begin{tabular}{|c|c|c|c|c|}
\hline \multirow{2}{*}{$\mathrm{N}$} & \multirow{2}{*}{$\mathrm{P}$} & \multirow{2}{*}{$\mathrm{K}$} & \multicolumn{2}{|c|}{$\begin{array}{c}\text { Produção de aveia nos sistemas } \\
\text { Oats yield }\end{array}$} \\
\hline & & & $\begin{array}{c}\text { Plantio convencional } \\
\text { Conventional tillage }\end{array}$ & $\begin{array}{c}\text { Plantio com cobertura } \\
\text { Mulch-covered }\end{array}$ \\
\hline & \multicolumn{2}{|c|}{$\mathrm{kg} \mathrm{ha}^{-1}$} & \multicolumn{2}{|c|}{$\mathrm{kg} \mathrm{ha}^{-1}$} \\
\hline 0 & 0 & 0 & 3483 & 3130 \\
\hline 0 & 60 & 70 & 3659 & 2971 \\
\hline 0 & 120 & 140 & 3571 & 2632 \\
\hline 0 & 180 & 210 & 4016 & 3224 \\
\hline 70 & 0 & 70 & 4998 & 5481 \\
\hline 70 & 60 & 0 & 4940 & 4996 \\
\hline 70 & 120 & 210 & 6098 & 5507 \\
\hline 70 & 180 & 140 & 6053 & 5654 \\
\hline 140 & 0 & 140 & 4831 & 6662 \\
\hline 140 & 60 & 210 & 5850 & 7266 \\
\hline 140 & 120 & 0 & 4437 & 7200 \\
\hline 140 & 180 & 70 & 6394 & 7181 \\
\hline 210 & 0 & 210 & 4975 & 6974 \\
\hline 210 & 60 & 140 & 5942 & 7871 \\
\hline 210 & 120 & 70 & 6939 & 8116 \\
\hline 210 & 180 & 0 & 5330 & 7627 \\
\hline 0 & 0 & 210 & 3868 & 2983 \\
\hline 0 & 60 & 140 & 2992 & 3622 \\
\hline 0 & 120 & 70 & 3904 & 3711 \\
\hline 0 & 180 & 0 & 3270 & 3551 \\
\hline 70 & 0 & 140 & 5622 & 5460 \\
\hline 70 & 120 & 0 & 4918 & 5424 \\
\hline 70 & 60 & 210 & 5881 & 5152 \\
\hline 70 & 180 & 70 & 5743 & 5773 \\
\hline 140 & 0 & 70 & 5794 & 6302 \\
\hline 140 & 60 & 0 & 4180 & 8057 \\
\hline 140 & 120 & 210 & 7042 & 8112 \\
\hline 140 & 180 & 140 & 7303 & 8059 \\
\hline 210 & 0 & 0 & 4346 & 6649 \\
\hline 210 & 60 & 70 & 5556 & 6981 \\
\hline 210 & 120 & 140 & 5956 & 9239 \\
\hline 210 & 180 & 210 & 7171 & 8181 \\
\hline Média & & 5158 & 5930 & \\
\hline Teste F & & & $\mathrm{N}_{\mathrm{L}}{ }^{* *} \mathrm{~N}_{\mathrm{Q}} * \mathrm{P}_{\mathrm{L}} * * \mathrm{P}_{\mathrm{Q}} *$ & $\mathrm{~N}_{\mathrm{L}}^{* *} \mathrm{~N}_{\mathrm{Q}}^{*}, \mathrm{P}_{\mathrm{L}}^{*}$ \\
\hline $\mathrm{CV}, \%$ & & & 8,7 & 6,6 \\
\hline
\end{tabular}

Em teste $\mathrm{F}$ são indicados somente os coeficientes significativos ao nível de $5\left(^{*}\right)$ e $1 \%\left(^{* *}\right)$.

In the $F$ test, only significant coefficients at $5\left({ }^{*}\right)$ and $1 \%\left(^{* *}\right)$ are indicated.

$\mathrm{NL}, \mathrm{NQ}=$ componente linear e quadrático para $\mathrm{N} ; \mathrm{N} \times \mathrm{P}=$ interação $\mathrm{N} \times \mathrm{P}$

$N L, N Q=$ linear and quadratic component for $N ; N \times P=N \times P$ interaction. 
maior parte dos meristemas apicais foi cortada, a rebrota veiu dos perfilhos basais e, então, foi mais demorada, mas no final do período, para se efetuar o segundo corte, as plantas conseguiram recuperar o desenvolvimento, confirmado pela produção de forragem nos demais tratamentos após o primeiro corte (Tabela 4).

No sistema convencional de plantio, verificou-se decréscimo de produção de forragem com os cortes. Já no plantio com cobertura morta, isto só ocorreu nos tratamentos com dose zero dos nutrientes, havendo aumento da produção de forragem no quarto corte para as outras doses. O nitrogênio foi o fator mais limitante na produção de forragem, principalmente para o plantio com cobertura (Tabela 4). Esse decréscimo parece estar relacionado com a redução gradual do número de perfilhos vigorosos, cujo remanescente foi maior na área com cobertura morta, que mantém maior uniformidade na umidade e temperatura na camada superficial do solo e, com isso, disponibilidade uniforme de nutrientes, beneficiando a recuperação da soqueira de aveia. Ao mesmo tempo, a cobertura morta permite o desenvolvimento de sistema radicular na camada mais superficial, onde ocorre troca mais intensa de gases, com aporte mais intenso de oxigênio, importante para plantas estimuladas para uma respiração mais intensa.

A análise da terra na área dos dois experimentos (Tabela 2) indicou teores baixos de fósforo (faixa de teores baixos para P-resina: 0 a $15 \mathrm{mg} \mathrm{dm}^{-3}$ ), segundo Van Raij et al. (1996). A análise de variância (Tabela 3) mostra que ocorreu resposta à aplicação desse nutriente para os dois sistemas de plantio, o que é esperado. Devido à maior extração de nutrientes pela forragem em relação aos grãos, as recomendações atuais de adubação para a produção de grãos de aveia de sequeiro no Estado de São Paulo (Camargo et al., 1996) são mais restritivas para a produção de forragem e a resposta à adubação. No caso do fósforo, a extração pela forragem: $35 \mathrm{~kg}$ de $\mathrm{P}_{2} \mathrm{O}_{5}$ para produzir $7 \mathrm{t} \mathrm{ha}^{-1}$ (Primavesi \& Primavesi, 2001), embora não seja muito maior que a extração para produzir $3 \mathrm{tha}^{-1} \mathrm{de}$ grãos: $21 \mathrm{~kg} \mathrm{ha}^{-1}$ de $\mathrm{P}_{2} \mathrm{O}_{5}$ (Cantarella et al., 1996), o manejo de cortes e conseqüente seqüência de morte e renovação da maior parte do sistema radicular, pode ocasionar demanda por maior quantidade

Tabela 4 - Produção média estimada de matéria seca de forragem de aveia por corte e total, nos dois sistemas de plantio

Table 4 - Estimated oat forage dry matter yield per cutting and total, on both planting systems

\begin{tabular}{|c|c|c|c|c|c|c|c|c|c|c|}
\hline \multirow{4}{*}{$\begin{array}{l}\text { Doses } \\
\text { Rates }\end{array}$} & \multicolumn{9}{|c|}{$\begin{array}{c}\text { Produção de matéria seca nos sistemas } \\
\text { Dry matter yield in systems }\end{array}$} & \\
\hline & \multicolumn{5}{|c|}{$\begin{array}{l}\text { Convencional } \\
\text { Conventional }\end{array}$} & \multicolumn{5}{|c|}{$\begin{array}{l}\text { Com cobertura } \\
\text { Mulch-covered }\end{array}$} \\
\hline & \multicolumn{5}{|c|}{$\begin{array}{l}\text { Cortes } \\
\text { Cuttings }\end{array}$} & \multicolumn{5}{|c|}{$\begin{array}{l}\text { Cortes } \\
\text { Cuttings }\end{array}$} \\
\hline & 1 & 2 & 3 & 4 & Total & 1 & 2 & 3 & 4 & Total \\
\hline & & & & & $\mathrm{kg} \mathrm{h}$ & & & & & \\
\hline \multicolumn{11}{|l|}{$\mathrm{N}$} \\
\hline 0 & 831 & 1191 & 1097 & 475 & 3595 & 699 & 990 & 1076 & 463 & 3228 \\
\hline 70 & 998 & 1873 & 1645 & 1015 & 5532 & 913 & 1654 & 1555 & 1309 & 5431 \\
\hline 140 & 1070 & 1933 & 1607 & 1118 & 5729 & 1133 & 2009 & 1776 & 2436 & 7354 \\
\hline 210 & 1169 & 1997 & 1573 & 1039 & 5777 & 1270 & 2103 & 1819 & 2513 & 7705 \\
\hline \multicolumn{11}{|l|}{$\mathrm{P}$} \\
\hline 0 & 831 & 1613 & 1384 & 912 & 4740 & 886 & 1501 & 1577 & 1491 & 5455 \\
\hline 60 & 898 & 1653 & 1453 & 871 & 4875 & 1039 & 1657 & 1520 & 1649 & 5864 \\
\hline 120 & 1112 & 1824 & 1528 & 855 & 5358 & 1013 & 1830 & 1540 & 1721 & 6242 \\
\hline 180 & 1228 & 1904 & 1568 & 1010 & 5660 & 1077 & 1770 & 1588 & 1860 & 6156 \\
\hline \multicolumn{11}{|l|}{$\mathrm{K}$} \\
\hline 0 & 1019 & 1559 & 1281 & 505 & 4363 & 967 & 1651 & 1660 & 1552 & 5829 \\
\hline 70 & 1029 & 1789 & 1609 & 946 & 5373 & 950 & 1644 & 1597 & 1624 & 5815 \\
\hline 140 & 966 & 1776 & 1519 & 1023 & 5284 & 1046 & 1789 & 1508 & 1808 & 6150 \\
\hline 210 & 1055 & 1870 & 1514 & 1174 & 5613 & 1053 & 1674 & 1460 & 1738 & 5925 \\
\hline
\end{tabular}

Datas dos cortes: $1=04 / 07 / 01 ; 2=08 / 08 / 01 ; 3=12 / 09 / 01 ; 4=17 / 10 / 01$.

Cutting dates: $1=07 / 04 / 01 ; 2=08 / 08 / 01 ; 3=09 / 12 / 01 ; 4=10 / 17 / 01$. 
disponível de fósforo em relação ao sistema em que são produzidos somente grãos.

Nos dois sistemas de plantio, as respostas às doses de $\mathrm{P}$ em produção de matéria seca aumentaram com o acréscimo das doses de $\mathrm{N}$, mas foram maiores para o sistema de plantio direto com palhada de milho (Tabela 5). A melhor resposta em produção ao aporte de nitrogênio e fósforo em área com cobertura morta, provavelmente, está relacionada com a melhor oxigenação do sistema radicular na interface solo-cobertura morta, bem como à manutenção do teor de água e temperatura mais uniforme na camada superficial. Redução na temperatura máxima do solo permite à planta retirar água do solo retida sob tensões mais elevadas.

No plantio convencional, a dinâmica da água e da temperatura no solo, devido à ausência de cobertura morta, pode estar afetando a difusão e a uniformidade da disponibilidade do fósforo, necessárias para a resposta ao $\mathrm{N}$ de gramíneas em estabelecimento. Doses maiores de fósforo podem neutralizar estas restrições, especialmente em solos de cerrado, que apresentam grande variabilidade espacial no conteúdo de nutrientes essenciais.

As equações relacionando produção de forragem e doses de N, P e K aplicadas nos dois sistemas de plantio, foram:

a) para o plantio convencional:

$$
\begin{gathered}
\mathrm{Y}=3.387+23,80 \mathrm{~N}-0,0963 \mathrm{~N}^{2}-4,071 \mathrm{P}+ \\
0,0116 \mathrm{P}^{2}+8,241 \mathrm{~K}-0,0348 \mathrm{~K}^{2}+0,0451 \mathrm{NP}+ \\
0,0191 \mathrm{NK}+0,0254 \mathrm{PK}
\end{gathered}
$$

b) para o plantio com cobertura:

$$
\begin{gathered}
\mathrm{Y} 1=3.108+36,74 \mathrm{~N}-0,0945 \mathrm{~N}^{2}+6,373 \mathrm{P}- \\
0,0344 \mathrm{P}^{2}+0,400 \mathrm{~K}-0,0107 \mathrm{~K}^{2}+0,0316 \mathrm{NP}+ \\
0,021 \mathrm{NK}+0,0061 \mathrm{PK}
\end{gathered}
$$

Os sistemas de plantio afetaram os níveis médios de produtividade de matéria seca de aveia, bem como as respostas dos nutrientes (Tabelas 3 e 4). A produtividade média de matéria seca foi de cerca de 5,2 e $5,9 \mathrm{t} \mathrm{ha}^{-1}$, respectivamente, sob plantio convencional e plantio com cobertura morta (Tabela 3 ). $\mathrm{O}$ aumento de produtividade devido ao $\mathrm{N}$ foi de aproximadamente $2,2 \mathrm{t} \mathrm{ha}^{-1}$ sob plantio convencional mas, atingiu 4,5 $\mathrm{t} \mathrm{ha}^{-1}$ na área com cobertura morta (Tabela 4). Os aumentos de produção de matéria seca de aveia devidos à adição de $\mathrm{K}$ foram bem menores e seguiram a tendência oposta: $1,25 \mathrm{t} \mathrm{ha}^{-1}$ em plantio convencional e $0,32 \mathrm{t} \mathrm{ha}^{-1} \mathrm{em}$ plantio com cobertura morta. A palhada no plantio com cobertura morta libera $\mathrm{K}$, o que pode explicar a baixa resposta às doses de $\mathrm{K}$, embora o solo apresentasse teores baixos desse nutriente. Para o $\mathrm{P}$ as respostas foram semelhantes nos dois sistemas, com incrementos de produção da ordem de 0,8 a 0,9 t ha $^{-1}$ de aveia (Tabela 4 ).

Os teores de N-nítrico residual presentes no solo foram semelhantes, na época do plantio da aveia, para ambos os sistemas de cultivo (Tabela 2), equivalentes a aproximadamente $100 \mathrm{~kg} \mathrm{ha}^{-1}$ de $\mathrm{N}$ até $60 \mathrm{~cm}$ de profundidade. A maior resposta ao $\mathrm{N} \mathrm{em}$ plantio direto pareceu estar associada ao melhor uso da água do que a maiores perdas de $\mathrm{N}$ por lixiviação ou desnitrificação, freqüientemente atribuídas às áreas de plantio direto (Thomas et al., 1973). No presente experimento, os rendimentos obtidos sem a adição de $\mathrm{N}$ foram semelhantes para os dois sistemas; no entanto, nas parcelas que receberam as maiores doses de $\mathrm{N}$, a produção de matéria seca de aveia foi cerca de $2 \mathrm{t} \mathrm{ha}^{-1}$ superior em plantio com cobertura morta (Tabela 4), portanto, com maior eficiência aparente de utilização do $\mathrm{N}$ fertilizante neste último sistema. Resultados semelhantes já haviam sido relatados em antigos experimentos comparando plantio convencional e plantio direto para a cultura do milho (Moscher \& Martens, 1975).

A ausência de resposta ao $\mathrm{K}$ nas parcelas em plantio com cobertura morta pode estar associada à reciclagem desse elemento, que normalmente é realizada pela cultura de cobertura. Os baixos teores de $\mathrm{K}$ mostrados na análise de solo (Tabela 2) podem não refletir todo o $\mathrm{K}$ disponível nas parcelas sob plantio com cobertura morta, pois, na época da amostragem do solo, as plantas de milho ainda estavam de pé, no campo. Os resíduos de milho (cerca de $9 \mathrm{t} \mathrm{ha}^{-1}$ de matéria seca) poderiam conter cerca de $100 \mathrm{~kg} \mathrm{ha}^{-1}$ de $\mathrm{K}_{2} \mathrm{O}$ (Hiroce et al., 1989), que retornam rapidamente ao solo em forma prontamente disponível para a cultura sucessora. Porém, no quarto corte da aveia com cobertura morta, a resposta à adubação potássica era evidente (Tabela 4), indicando o esgotamento das reservas do solo e/ou do K reciclado pela cultura de cobertura.

As doses de fertilizantes para máximo retorno econômico de matéria seca de aveia, produzida em quatro cortes consecutivos e com irrigação, foram, respectivamente, de 160,180 e $180 \mathrm{~kg} \mathrm{ha}^{-1}$ de $\mathrm{N}, \mathrm{P}_{2} \mathrm{O}_{5}$ e $\mathrm{K}_{2} \mathrm{O}$, no cultivo convencional, e de 200,120 e $95 \mathrm{~kg} \mathrm{ha}^{-1}$ de N, $\mathrm{P}_{2} \mathrm{O}_{5}$ e $\mathrm{K}_{2} \mathrm{O}$, no sistema de plantio com cobertura de solo (Tabela 6). Estes resultados estão próximos dos obtidos em plantio convencional, em um LVAd, com aveia cultivar São Carlos, produzida em 
sistema de cortes, com irrigação (Primavesi et al., 2001b). Todavia, as doses econômicas para a produção de aveia para forragem são muito superiores àquelas recomendadas para a produção de grãos de aveia no Estado de São Paulo. As recomendações atuais indicam valores máximos de 70, 90 e $60 \mathrm{~kg} \mathrm{ha}^{-1}$ de $\mathrm{N}, \mathrm{P}_{2} \mathrm{O}_{5} \mathrm{e}$ $\mathrm{K}_{2} \mathrm{O}$, respectivamente, para condições de sequeiro (Camargo et al., 1996), que, porém, são mais restritivas para a produção e a resposta à adubação.

Considerando a exportação de nutrientes por aproximadamente $7 \mathrm{t} \mathrm{ha}^{-1}$ de matéria seca de aveia de 175,35 e $253 \mathrm{~kg} \mathrm{ha}^{-1}$ de $\mathrm{N}, \mathrm{P}_{2} \mathrm{O}_{5}$ e $\mathrm{K}_{2} \mathrm{O}$ (com base na média dos teores foliares de plantas de três cultivares de aveia forrageira cortadas com intervalos de 35 dias, de $25,2,2$ e $30 \mathrm{~g} \mathrm{~kg}^{-1}$ de $\mathrm{N}, \mathrm{P}$ e K) ( Primavesi \& Primavesi. 2001c), verifica-se que a dose de $\mathrm{K}$ recomendada para produção de forragem de aveia no sistema de plantio com cobertura morta, está bem abaixo da extração desse nutriente para essa produção de forragem, sinalizando novamente para um possível fornecimento de K pela palhada, visto o solo apresentar teores baixos de $\mathrm{K}$.

Nos dois sistemas de plantio, o nitrogênio apresentou o maior retorno em produção de forragem por

Tabela 5 - Produção estimada de matéria seca de forragem de aveia para as doses de $\mathrm{N}$ e de $\mathrm{P}\left(\mathrm{kg} \mathrm{ha}^{-1}\right)$, nos dois sistemas de plantio

Table 5 - Estimated oat dry matter forage yield for $N$ and $P$ rates $\left(\mathrm{kg} \mathrm{ha}^{-1}\right)$, on both planting system

\begin{tabular}{|c|c|c|c|c|}
\hline \multirow[t]{2}{*}{$\begin{array}{l}\text { Doses de } \mathrm{P}_{2} \mathrm{O}_{5} \\
\text { Rates of } \mathrm{P}_{2} \mathrm{O}_{5}\end{array}$} & \multicolumn{4}{|c|}{$\begin{array}{c}\text { Produção de forragem para as doses de } \mathrm{N} \text {, em kg ha-1 } \\
\text { Forage yields for } \mathrm{N} \text { rates, in } \mathrm{kg} \mathrm{ha}^{-1}\end{array}$} \\
\hline & 0 & 70 & 140 & 210 \\
\hline $\mathrm{kg} \mathrm{ha}^{-1}$ & 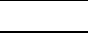 & 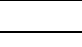 & & \\
\hline & & $\begin{array}{l}\text { conv } \\
\text { itiona }\end{array}$ & & \\
\hline 0 & 3675 & 5310 & 5312 & 4660 \\
\hline 60 & 3326 & 5400 & 5015 & 5749 \\
\hline 120 & 3737 & 5508 & 5730 & 6448 \\
\hline 180 & 3643 & 5898 & 6848 & 6251 \\
\hline & & $\begin{array}{l}\text { com } \\
\text { lch-co }\end{array}$ & & \\
\hline 0 & 3057 & 5470 & 6482 & 6811 \\
\hline 60 & 3297 & 5074 & 7620 & 7426 \\
\hline 120 & 3172 & 5465 & 7656 & 8678 \\
\hline 180 & 3387 & 5714 & 7620 & 7904 \\
\hline
\end{tabular}

Tabela 6 - Doses de $\mathrm{N}, \mathrm{P}_{2} \mathrm{O}_{5}$ e $\mathrm{K}_{2} \mathrm{O}$ para máxima produção agronômica e econômica de forragem de aveia

Table $6-\quad \mathrm{N}_{2} \mathrm{P}_{2} \mathrm{O}_{5}$ and $\mathrm{K}_{2} \mathrm{O}$ rates for maximum agronomic and economical oat forage yields

\begin{tabular}{|c|c|c|c|c|c|c|}
\hline \multirow{2}{*}{$\begin{array}{l}\text { Sistemas de plantio } \\
\text { Planting systems }\end{array}$} & \multicolumn{3}{|c|}{$\begin{array}{l}\text { Máxima produção agronômica } \\
\text { Maximum agronomic yield }\end{array}$} & \multicolumn{3}{|c|}{$\begin{array}{c}\text { Máxima receita líquida }{ }^{*} \\
\text { Maximum profit }\end{array}$} \\
\hline & $\mathrm{N}$ & $\mathrm{P}_{2} \mathrm{O}_{5}$ & $\mathrm{~K}_{2} \mathrm{O}$ & $\mathrm{N}$ & $\mathrm{P}_{2} \mathrm{O}_{5}$ & $\mathrm{~K}_{2} \mathrm{O}$ \\
\hline & & & $-\mathrm{k}$ & & & \\
\hline $\begin{array}{l}\text { Convencional } \\
\text { Conventional }\end{array}$ & 185 & 180 & 210 & 160 & 180 & 180 \\
\hline Com cobertura & 210 & 180 & 210 & 200 & 120 & 95 \\
\hline
\end{tabular}

Mulch-covered

Plantio convencional: produção máxima $=7534 \mathrm{~kg} \mathrm{ha}^{-1}$; produção na dose mais econômica $=7398 \mathrm{~kg} \mathrm{ha}^{-1}$. Plantio com cobertura: produção máxima $=8646 \mathrm{~kg} \mathrm{ha}^{-1}$; produção na dose mais econômica $=$ $8111 \mathrm{~kg} \mathrm{ha}^{-1}$. "Calculado com os seguintes preços $\left(R \$ \mathrm{~kg}^{-1}\right)$ : de $\mathrm{N}=1,07$; de $\mathrm{P}_{2} \mathrm{O}_{5}=1,38$; de $\mathrm{K}_{2} \mathrm{O}=0,82$. Feno de aveia $\left(\mathrm{R} \$ \mathrm{~kg}^{-1}\right)=0,22$.

Conventional tillage: maximum yield $=7534 \mathrm{~kg} \mathrm{ha}^{-1}$; yield on the maximum profit $=7398 \mathrm{~kg} \mathrm{ha}^{-1}$.

No-till: maximum yield $=8646 \mathrm{~kg} \mathrm{ha}^{-1} ;$ yield on the maximum profit $=8111 \mathrm{~kg} \mathrm{ha}^{-1}$.

${ }^{*}$ Estimated with the following prices: $\left(R \$ \mathrm{~kg}^{-1}\right): N=1.07 ; \mathrm{P}_{2} \mathrm{O}_{5}=1.38 ; K_{2} \mathrm{O}=0.82$. Oat hay $\left(R \$ \mathrm{~kg}^{-1}\right)=0.22$. 
unidade de nutriente aplicado, com o sistema de plantio com cobertura morta apresentando o maior retorno. Em experimento realizado em ano anterior em Latossolo Vermelho Distrófico típico, com essa mesma linhagem de aveia, verificou-se menor eficiência do $\mathrm{N}$ no sistema de plantio com cobertura morta, atribuída à parcial imobilização do $\mathrm{N}$ pela palhada (Primavesi et al., 2002). No plantio com cobertura morta, verificou-se um potencial de produção $14 \%$ maior que o do plantio convencional.

\section{Conclusões}

Ocorreram respostas para o nitrogênio e fósforo, nos dois sistemas de plantio, e para o $\mathrm{K}$, apenas no plantio convencional.

A produção de forragem de aveia foi maior em sistemas de plantio com cobertura morta.

No sistema de plantio convencional, o máximo retorno econômico em produção de forragem ocorreu, respectivamente, nas doses 160,180 e $180 \mathrm{~kg} \mathrm{ha}^{-1} \mathrm{de}$ $\mathrm{N}, \mathrm{P}_{2} \mathrm{O}_{5}$ e $\mathrm{K}_{2} \mathrm{O}$. Os valores correspondentes para o plantio com cobertura de palha de milho foram 200, 120 e $95 \mathrm{~kg} \mathrm{ha}^{-1}$ de $\mathrm{N}, \mathrm{P}_{2} \mathrm{O}_{5}$ e $\mathrm{K}_{2} \mathrm{O}$.

\section{Literatura Citada}

ALMEIDA, F.S. Controle de ervas. In: Plantio direto no Estado do Paraná. Londrina: Fundação Instituto Agronômico do Paraná, 1981. p.101-144. (Circular, 23)

ANDRADE, D.F.; NOLETO, A.Q. Exemplos de fatoriais fracionados $(1 / 2) 4^{3}$ e $(1 / 4)^{4}$ para o ajuste de modelos polonomiais quadráticos. Pesquisa Agropecuária Brasileira, v.21, p.677-680, 1986.

CAMARGO, C.E.O.; FREITAS, J.G.; CANTARELLA. H. Aveia e centeio. In: Van RAIJ, B.; CANTARELLA, H.; QUAGGIO, J.A. et al. (Eds.) Recomendações de adubação e calagem para o Estado de São Paulo. Campinas: Instituto Agronômico, 1996. p. 52-53. (Boletim Técnico, 100)

CANTARELLA, H.; Van RAIJ, B.; CAMARGO, C.E.O. Cereais. In: Van RAIJ, B.; CANTARELLA, H.; QUAGGIO, J.A. et al. (Eds.) Recomendações de adubação e calagem para o Estado de São Paulo. Campinas, Instituto Agronômico. 1996. p.45-71. (Boletim Técnico, 100)

FRIZZONE, J.A.; TEODORO, R.E.F.; PEREIRA, A.S et al. Lâminas de água e doses de nitrogênio na produção de aveia (Avena sativa L.) para forragem. Scientia Agricola, v.52, p.578-586, 1995.

GODOY, R.; REIS, R.A.; HERLING, V.R. et al. Ensaio regional de aveia forrageira no Estado de São Paulo, 1997. In: REUNIÃO DA COMISSÃO BRASILEIRA DE PESQUISA DE AVEIA, 18., 1998, Londrina. Resumos... Londrina: Comissão Brasileira de Pesquisa de Aveia, 1998. p.391-394.

HIROCE, R.; FURLANI, A.M.C.; LIMA, M. Extração de nutrientes na colheita por populações e híbridos de milho. Campinas: Instituto Agronômico. 1989. 24p. (Boletim Científico, 17)
KOCHHANN, R.A; DENARDIN, J.E. Comportamento das culturas de trigo, soja e milho à adubação fosfatada nos sistemas plantio direto e preparo convencional, 1997. In: SEMINÁRIO INTERNACIONAL DO SISTEMA PLANTIO DIRETO, 2., 1997, Passo Fundo. Anais... Passo Fundo: EMBRAPA-CNPT, 1997. p.243-246.

MOSCHLER, W.W.; MARTENS, D.C. Nitrogen, phosphorus, and potassium requirement in no-tillage and conventionally tilled corn. Soil Science Society of America Proceedings, v.39, p.886-891, 1975.

PRIMAVESI, A.C.; PRIMAVESI, O.; CHINELLATO, A. et al. Indicadores de determinação de cortes de cultivares de aveia forrageira. Scientia Agricola, v.58, p.79-89, 2001a.

PRIMAVESI, A.C.; PRIMAVESI, O.; CANTARELLA, H. et al. Resposta da aveia cultivar São Carlos à adubação NPK, em dois tipos de solo, no Estado de São Paulo. Revista de Agricultura, v.76, n.3, p.317-330, 2001b.

PRIMAVESI, A.C.; PRIMAVESI, O. Efeito de intervalos de corte e de épocas de plantio sobre os teores de minerais em cultivares de aveia. Revista de Agricultura, v.76, n.1, p.3-18, 2001c.

PRIMAVESI, A.C.; PRIMAVESI, O. CANTARELLA, H. et al. Recomendação de adubação para aveia, em dois sistemas de plantio, em Latossolo Vermelho Distrófico típico. São Carlos: Embrapa Pecuária Sudeste, 2002. 6p (Comunicado Técnico, 34)

RASSINI, J.B. Manejo da água na irrigação da alfafa num Latossolo Vermelho-Amarelo. Pesquisa Agropecuária Brasileira, v.37, n.4, p.503-507, 2001.

RESENDE, M. Clima do solo e suas relações com o ambiente agrícola. Informe Agropecuário, v.12, p.43-59, 1986.

SÁ, J.C.M. Manejo da fertilidade do solo no plantio direto. Castro: Fundação ABC. 1993. 96p.

STATISTICAL ANALYSIS SYSTEM - SAS. SAS/STAT user's guide: statistics, versão 6. 4.ed. Cary: 1993. v.2, 1686p.

SEDIYAMA, G.C.; PRATES, J.E. O microclima: possibilidades de modificação. Informe Agropecuário, v. 12, p.38-42, 1986.

THOMAS, G.W.; BLEVINS, R.L.; PHILLIPS, R.E. et al. Effect of a killed sod mulch on nitrate movement and corn yield. Agronomy Journal, v.65, p.736-739, 1973.

UNGER, P.W. Straw mulch effects on soil temperatures and sorghum germination and growth. Agronomy Journal, v.70, n.5, p.858-864, 1978.

Van RAIJ, B.; ANDRADE, J.C.; CANTARELLA, H.; QUAGGIO, J.A. Análise química para avaliação da fertilidade de solos tropicais. Campinas: Instituto Agronômico, 2001. 285p.

Van RAIJ, B.; QUAGGIO, J.A.; CANTARELLA, H. et al. Interpretação de resultados de análise de solo. In: Van RAIJ, B.; CANTARELlA, H.; QUAGGIO, J.A. et al. (Eds.) Recomendações de adubação e calagem para o Estado de São Paulo. Campinas: Instituto Agronômico, 1996. p.8-13. (Boletim Técnico, 100)

VIEIRA, M.J. Propriedades físicas do solo. In: Plantio direto no Estado do Paraná. Londrina: Fundação Instituto Agronômico do Paraná, 1981, p.19-32 (Circular, 23). 